\title{
Almond Consumption and Processing Affects the Composition of the Gastrointestinal Microbiota of Healthy Adult Men and Women: A Randomized Controlled Trial
}

\author{
Hannah D. Holscher ${ }^{1,2, *}$, Andrew M. Taylor ${ }^{1}$, Kelly S. Swanson ${ }^{2,3}$, Janet A. Novotny ${ }^{4}$ \\ and David J. Baer 4 \\ 1 Department of Food Science and Human Nutrition, University of Illinois, Urbana, IL 61801, USA; \\ amtaylr3@illinois.edu \\ 2 Division of Nutritional Sciences, University of Illinois, Urbana, IL 61801, USA; ksswanso@illinois.edu \\ 3 Department of Animal Sciences, University of Illinois, Urbana, IL 61801, USA \\ 4 USDA, ARS, Beltsville Human Nutrition Research Center, Beltsville, MD 20705, USA; \\ Janet.Novotny@ARS.USDA.GOV (J.A.N.); David.Baer@ARS.USDA.GOV (D.J.B.) \\ * Correspondence: hholsche@illinois.edu; Tel.: +1-217-300-2512
}

Received: 6 October 2017; Accepted: 23 January 2018; Published: 26 January 2018

\begin{abstract}
Background: Almond processing has been shown to differentially impact metabolizable energy; however, the effect of food form on the gastrointestinal microbiota is under-investigated. Objective: We aimed to assess the interrelationship of almond consumption and processing on the gastrointestinal microbiota. Design: A controlled-feeding, randomized, five-period, crossover study with washouts between diet periods was conducted in healthy adults $(n=18)$. Treatments included: (1) zero servings/day of almonds (control); (2) 1.5 servings (42 g)/day of whole almonds; (3) 1.5 servings/day of whole, roasted almonds; (4) 1.5 servings/day of roasted, chopped almonds; and (5) 1.5 servings/day of almond butter. Fecal samples were collected at the end of each three-week diet period. Results: Almond consumption increased the relative abundances of Lachnospira, Roseburia, and Dialister $(p \leq 0.05)$. Comparisons between control and the four almond treatments revealed that chopped almonds increased Lachnospira, Roseburia, and Oscillospira compared to control $(p<0.05)$, while whole almonds increased Dialister compared to control $(p=0.007)$. There were no differences between almond butter and control. Conclusions: These results reveal that almond consumption induced changes in the microbial community composition of the human gastrointestinal microbiota. Furthermore, the degree of almond processing (e.g., roasting, chopping, and grinding into butter) differentially impacted the relative abundances of bacterial genera.
\end{abstract}

Keywords: nuts; microbiome; fiber; fat; fermentation

\section{Introduction}

Diet is a contributing factor to the development of numerous diseases including obesity, cardiovascular disease, and type 2 diabetes. Increasingly, these complex metabolic diseases are also being associated with the gastrointestinal microbiota [1]. The gastrointestinal microbiota, an ecosystem containing trillions of microorganisms, including bacteria, archaea, and fungi, is, in essence, a microbial organ that possesses more than 150 times more genes than the human genome [2]. Importantly, these microbes possess genes that allow for the metabolism of foods that escape digestion by human alimentary enzymes, thereby aligning diet as an important modulator of the interrelationship between diet, the gastrointestinal microbiota, and host health.

Diet is a key modulator of the human gastrointestinal microbiota-habitual dietary patterns [3], rapid changes in dietary macronutrient composition [4], eating behaviors [5], and increased intake of 
different types of plant-based foods [6] have been linked to the composition of human gastrointestinal microbiota. To date, much of the research on specific diet components has focused on the impact of consumption of different dietary fibers and prebiotics on the human gastrointestinal microbiota [7-10]. These studies have revealed that the molecular composition, including the glycosidic linkages between monosaccharides, as well as physicochemical properties of fibers influence the microbial composition and production of bacterial metabolites including short-chain fatty acids [11]. Preclinical research and in vitro studies have also demonstrated that dietary fats can differentially impact the gut microbiota and that certain microbes can utilize fatty acids as energy substrates [12-15]. Almonds are a nutrient-dense food that provide a good source of dietary fiber ( $5 \mathrm{~g}$ per $42 \mathrm{~g}$ almonds) as well as unsaturated fatty acids ( $20 \mathrm{~g}$ per $42 \mathrm{~g}$ almonds).

Dietary consumption of nuts is associated with reduced risk of diseases including, obesity, cardiovascular disease, type 2 diabetes, and cancer [16,17]. Furthermore, epidemiological evidence indicates that individuals who regularly consume tree nuts exhibit lower waist circumference and superior metabolic profiles [18]. Interestingly, clinical trials with almonds have demonstrated that food form (e.g., whole, chopped, ground) differentially impacts metabolizable energy due to incomplete absorption of macronutrients in the gastrointestinal tract [19]. As nutrients that are not absorbed in the proximal gastrointestinal tract are subject to microbial fermentation, dietary consumption of nuts in different forms stand to influence the composition of the gastrointestinal microbiota. Indeed, the health-related effects of nut consumption may not only be related to their metabolizable energy, but also their impact on the gastrointestinal microbiota. One hypothesized connection between the metabolic improvements shown with almond consumption is increased butyrate production by gastrointestinal microbes. In vitro, microbial fermentation of finely ground almonds has been shown to increase butyrate concentrations [20], and preclinical studies have demonstrated that increased butyrate concentrations are linked to reduced gut inflammation [21], improved gut barrier function [22], and glucose tolerance [23].

Previously, we conducted a controlled-feeding, randomized, cross-over trial in healthy adult men and women to determine the metabolizable energy of different forms of almonds, including whole, natural almonds; whole, roasted almonds; roasted, chopped almonds; and almond butter and reported that the metabolizable energy of whole natural almonds, whole roasted almonds, and chopped almonds was up to $25 \%$ lower than predicted by calculation using the Atwater values [19]. Indeed, the process of roasting and chopping almonds reduced their hardness and particle size, increasing the digestion and absorption of lipids in the small intestine, which resulted in metabolizable energy values of $4.42 \mathrm{kcal} / \mathrm{g}$ for whole natural, $4.86 \mathrm{kcal} / \mathrm{g}$ for whole roasted, and $5.04 \mathrm{kcal} / \mathrm{g}$ for roasted chopped almonds. The addition of pureeing the roasted almonds into butter ablated this inhibition of digestion and absorption revealing that the calculated and measured metabolizable energy of almond butter was not different, $6.68 \mathrm{kcal} / \mathrm{g}$ and $6.53 \mathrm{kcal} / \mathrm{g}$, respectively. Thus, the degree of almond processing (e.g., roasting, chopping, and grinding) affected the nutrients delivered to the large intestine and excreted in the feces. In this follow-up report, we aimed to assess our secondary outcomes of the study and determine the effect of almond consumption and processing on the gastrointestinal microbiota by subjecting the same fecal samples from the clinical trial on metabolizable energy of almonds to high-throughput sequencing. The objectives of the current study were to determine how almond consumption and almond form (e.g., whole, whole roasted, chopped, and butter) differentially impact the bacteria, archaea, and fungi in the human gastrointestinal tract. We hypothesized that consumption of almonds and food form would impact the human fecal microbiota compared to control.

\section{Methods}

\subsection{Experimental Design, Treatments, and Subjects}

This report is a follow-up to a previously conducted clinical trial (NCT02034383). Details of the design and results of the primary study, which assessed the metabolizable energy of almonds, were previously reported [19]. Herein, secondary outcomes related to almond consumption on 
the gastrointestinal microbiota were assessed. Briefly, this was a controlled-feeding, randomized, cross-over study with five three-week diet periods, each diet period was separated by a one-week non-controlled diet break (wash-out) period. The controlled diets, fed at weight maintenance, consisted of a base diet designed to represent the typical American diet, with a macronutrient composition of $53 \%$ of kcals from carbohydrates, $32 \%$ of kcals from fat, and $15 \%$ of kcals from protein, and $0 \mathrm{~g} / \mathrm{day}$ of almonds. All foods were identical between the control and almond diets, except for the almonds. During the four almond diet periods of the study, the controlled diet was scaled down to allow for the isocaloric inclusion of $42 \mathrm{~g}$ /day of varying forms of almonds: whole, natural almonds; whole, dry roasted almonds; chopped, dry roasted almonds; and dry roasted, almond butter.

Study participants were recruited in the Washington, DC metropolitan area surrounding the Beltsville Human Nutrition Research Center (BHNRC) in Beltsville, MD, USA. All subjects gave their informed consent for inclusion before participating in the study. The study was conducted in accordance with the Declaration of Helsinki, and the protocol and informed consent document were reviewed and approved by the Medstar Health Research Institute (Protocol \#2013-136). Participants were excluded if they were $<25$ or $>75$ years of age, had a body mass index (BMI) $<20$ or $>38 \mathrm{~kg} / \mathrm{m}^{2}$, blood pressure $\geq 160 / 100 \mathrm{~mm} \mathrm{Hg}$, fasting blood glucose $\geq 126 \mathrm{mg} / \mathrm{dL}$, fasting total blood cholesterol $\geq 280 \mathrm{mg} / \mathrm{dL}$, and fasting triglycerides $\geq 300 \mathrm{mg} / \mathrm{dL}$. Participants were excluded if they had any of the following diseases or conditions: allergy to almonds or other nuts, gastrointestinal disease, malabsorptive syndromes, liver disease, pancreatic disease, kidney disease, gout, hyperthyroidism, untreated or unstable hypothyroidism, certain cancers, or type II diabetes; history of bariatric or certain other surgeries related to weight control; history of eating disorders or other dietary patterns which are not consistent with the dietary intervention (e.g., vegetarians, very low fat diets, high protein diets); greater than 10\% change in body weight within the last 12 months; pregnant women or women who plan on becoming pregnant during the study period; women who had given birth within the past 12 months; and tobacco users. A random number generator was utilized for study participant randomization following the creation of a randomization scheme that stratified the 18 participants (10 males; eight females) by sex and BMI. Each participant was assigned to a treatment sequence that consisted of each of the five diet periods.

\subsection{Sample Collection and Analysis}

Fecal samples were collected at the end of each of the five diet treatment periods (e.g., control, whole almonds, whole roasted almonds, roasted chopped almonds, and almond butter) for microbiota analyses. Following fecal collection and homogenization, samples were stored at $-80{ }^{\circ} \mathrm{C}$ at the BHNRC prior to overnight shipment on dry ice to the University of Illinois and subsequent storage of samples at $-80{ }^{\circ} \mathrm{C}$ until analysis. Fecal DNA was extracted according to manufacturer's guidelines using the MoBio Powerlyzer Powersoil Kit (MoBIO Laboratories Inc., Carlsbad, CA, USA). After extraction, sequencing was performed at the W. M. Keck Center for Biotechnology at the University of Illinois as previously described [24]. Briefly, bacterial (V4 region of 16S rRNA; 515F/806R: 5'-GTGCCAGCMGCCGCGGTAA, 5'-GGACTACHVGGGTWTCTAAT), archaeal (ArchaeaF / ArchaeaR: 5'-GYGCASCAGKCGMGAAW, 5'-GGACTACVSGGGTATCTAAT) and fungal (ITS1F/ITS4R: 5'-TTCGTAGGTGAACCTGCGG, 5'-TCCTCCGCTTATTGATATGC) genes were amplified using a Fluidigm access array (Fluidigm, South San Francisco, CA, USA). Following amplification, a fragment analyzer (Advanced Analytics, Ames, IA, USA) was utilized to check the quality of the amplicon pool and confirm amplicon region and size. Next, a DNA pool was generated by combining equimolar amounts of the amplicon from each sample. Then, amplicon pools were size-selected on a $\%$ agarose E-gel (Life Technologics, Grand Island, NY, USA) to remove low molecular weight DNA fragments. A Qiagen gel purification kit (Qiagen, Valencia, CA, USA) was used to extract the amplicon pools from the gel and remove impurities. Then, size-selected, cleaned amplicon pools were analyzed using an Agilent Bioanalyzer (Advanced Analytics, Ames, IA, USA) to confirm size selection and quality. Lastly, the amplicon pool was sequenced using an Illumina MiSeq (Illumina Inc., San Diego, CA, USA) with version 3 chemistry. 
Sequence data derived from the sequencing process were trimmed using the the open access FASTX-toolkit ( $\mathrm{v}$ 0.0.14), and demultiplexed and analyzed with the open access bioinformatics software QIIME 1.8.0. Briefly, bacterial and archaeal sequences were clustered into operational taxonomic units (OTUs) using the default UCLUST closed-reference OTU picking algorithm (pick_closed_reference_otus.py) against the curated Greengenes 13_8 reference OTU database ( $97 \%$ similarity threshold), which discards sequences that do not match to the reference database $[25,26]$. Fungal OTUs were generated using the open reference OTU picking algorithm (pick_open_reference_otus.py) against the UNITE OTUs ITS 12_11 reference database [27]. Singletons (OTUs observed fewer than two times) and OTUs that represented less than $0.005 \%$ of the total observations were removed [28] before rarefying the bacterial sequences to an even sampling depth of 8227 sequences per sample to assess alpha (observed OTUs and phylogenetic diversity) and beta diversity (weighted and unweighted Unifrac distances) measures as well as the impact of treatment on OTU abundances that that represented $\geq 0.5 \%$ of the total sequences.

\subsection{Statistics}

Sequence percentages were analyzed using the mixed models procedure of SAS (version 9.4; SAS Institute, Inc., Cary, NC, USA) with treatment as a fixed effect and participant and period as random effects. Post hoc Dunnets adjustments were used to control for multiple comparisons. To determine if the presence or absence of almonds affected the fecal microbiota, contrast statements were utilized to compare almond (pooled whole, whole roasted, chopped, and butter) to the control diet period. To assess the effect of processing on the microbiota, each almond group (e.g., whole, whole roasted, chopped, or butter) was contrasted against control. The UNIVARIATE procedure and Shapiro-Wilk statistic were used to test for data normality, and log transformations were utilized as needed. The Wilcoxon test was used for fungal count analyses. A probability of $p \leq 0.05$ was accepted as statistically significant, and $p \leq 0.10$ was considered a trend.

\section{Results}

All 18 participants, 10 men and eight women, that were randomized completed the study. Participants had a mean BMI of $29.7+4.4 \mathrm{~kg} / \mathrm{m}^{2}$ and an age of $56.7+10.2$ years (Table 1 ).

Following demultiplexing and quality filtering, the mean and standard deviation of bacterial OTUs identified using closed reference OTU picking was 33,194 \pm 9686 , with a minimum of 8227 counts per sample. As such, all samples were rarefied to an even sequencing depth of 8227 for subsequent analyses. At the phyla level, more than $90 \%$ of bacterial sequences were dominated by Firmicutes (64.2\%) and Bacteroidetes (27.5\%), with smaller proportions of Actinobacteria $(3.8 \%)$, Proteobacteria $(2.0 \%)$ and Verrucomicrobia $(1.6 \%)$. Forty bacterial families were identified. The top seven families, Ruminococcaceae $(28.9 \%)$, Lachnospiraceae $(20.4 \%)$, Bacteroidaceae $(21.0 \%)$, an undefined family in the Clostridales order (8.1\%), Veillonellacaea (3.3\%), Bifodobacteriaceae $(2.5 \%)$, and Verrucomicrobiaceae (1.6\%), comprised approximately $90 \%$ of the sequences. Seventy-eight genera were classified with 21 representing greater than $90 \%$ of total sequences and 34 representing $<1 \%$; the top 10 genera, Bacteroides, unclassified Ruminococcaceae, unclassified Clostridiales, an unclassified Lachnospiraceae, Coprococcus, Faecalibacterium, Ruminococcus, Bifidobacterium, Blautia, and an unclassified genera in the Rikenellacaeae family represented approximately $77 \%$ of total sequences classified at the genera level.

Archaeal sequences accounted for approximated $8.4 \%$ of total sequences. Following demultiplexing and quality filtering, the mean and standard deviation of archaeal OTUs identified using closed reference OTU picking was $3081 \pm 5289$, with a maximum of 26,030 counts per sample and a minimum of zero counts per sample. Treatment did not impact archaea relative abundances. Fungi accounted for approximately $0.1 \%$ of total sequences; the mean and standard deviation was $256+560$ OTUs per sample. The minimum was one OTU/sample (12 individuals), and the maximum was 2410 sequences. Study participants had more $(p<0.05)$ fungal OTUs when consuming the whole almonds treatment compared to the other treatment groups. 
To determine if the presence or absence of almonds in the diet affected the fecal microbiota, contrast statements were utilized to compare almond (pooled whole, whole roasted, chopped, and butter) to the control diet period. The data revealed that almond consumption decreased the relative abundance of the Actinobacteria phylum, as well as Bifidobacterium and Parabacteroides $(p<0.05)$. The relative abundance of Lachnospira, Roseburia, Clostridium, and Dialister $(p \leq 0.05)$ increased when the almonds were consumed compared to the control (Table 2). To assess the effect that processing has on the microbiota, each almond group (e.g., whole, whole roasted, chopped, or butter) was contrasted against the control. These results revealed that processing differentially impacted the microbiota. Compared to the control, chopped almonds increased the relative abundance of Lachnospira, Roseburia, and Oscillospira $(p<0.05)$; whole roasted almonds increased $(p=0.03)$ the relative abundance of Lachnospira; and whole raw almonds increased $(p=0.007)$ the relative abundance of Dialister (Table 3). There were no differences between control and almond butter. Almond consumption did not affect bacterial alpha diversity or beta diversity measures (Supplemental Figures S1-S4).

Table 1. Baseline characteristics of the 10 male and eight female participants who consumed control or almond diets, each for three weeks.

\begin{tabular}{ccc}
\hline Characteristics & Values $^{\mathbf{1}}$ & Range \\
\hline Age, year & $56.7 \pm 10.2$ & $32.7-72.4$ \\
BMI, $\mathrm{kg} / \mathrm{m}^{2}$ & $29.7 \pm 4.4$ & $21.9-36.1$ \\
LDL cholesterol, mg/dL & $121 \pm 22.3$ & $82.5-153$ \\
HDL cholesterol, $\mathrm{mg} / \mathrm{dL}$ & $57.9 \pm 16.9$ & $33.3-85.5$ \\
Triglycerides, $\mathrm{mg} / \mathrm{dL}$ & $102 \pm 37.2$ & $52.4-200$ \\
Glucose, $\mathrm{mg} / \mathrm{dL}$ & $94.8 \pm 8.0$ & $81.9-108$ \\
\hline
\end{tabular}

${ }^{1}$ Values are means \pm SD.

Table 2. Bacterial phyla and genera of human participants at the end of the control condition as compared to the end of the almond diet conditions.

\begin{tabular}{|c|c|c|c|}
\hline \multicolumn{4}{|c|}{ Almond Consumption, $\%$ of Bacterial Sequences ${ }^{1}$} \\
\hline & Control (0 g/Day) & Almond (42 g/Day) & $p$-Value \\
\hline \multicolumn{4}{|l|}{ Phyla and Genera } \\
\hline Firmicutes & $63.9 \pm 1.99$ & $65.6 \pm 1.51$ & 0.29 \\
\hline Faecalibacterium & $4.39 \pm 0.68$ & $4.61 \pm 0.64$ & 0.47 \\
\hline Coprococcus & $4.54 \pm 0.54$ & $4.70 \pm 0.47$ & 0.65 \\
\hline Ruminococcus & $4.65 \pm 0.70$ & $4.16 \pm 0.59$ & 0.32 \\
\hline Blautia & $2.09 \pm 0.33$ & $2.25 \pm 0.30$ & 0.41 \\
\hline Dorea & $1.61 \pm 0.28$ & $1.69 \pm 0.26$ & 0.61 \\
\hline Phascolarctobacterium ${ }^{2}$ & $0.23 \pm 0.29$ & $0.21 \pm 0.28$ & 0.67 \\
\hline Roseburia $^{2}$ & $0.47 \pm 0.14$ & $0.67 \pm 0.13$ & 0.03 \\
\hline Lachnospira $^{2}$ & $0.49 \pm 0.15$ & $0.71 \pm 0.14$ & 0.01 \\
\hline Dialister & $0.42 \pm 0.31$ & $0.72 \pm 0.29$ & 0.05 \\
\hline Clostridium $^{2}$ & $0.42 \pm 0.08$ & $0.53 \pm 0.07$ & 0.04 \\
\hline Streptococcus ${ }^{2}$ & $0.17 \pm 0.18$ & $0.17 \pm 0.16$ & 0.95 \\
\hline Oscillospira & $0.54 \pm 0.07$ & $0.57 \pm 0.06$ & 0.56 \\
\hline Bacteroidetes & $25.7 \pm 2.13$ & $26.7 \pm 1.65$ & 0.57 \\
\hline Bacteroides & $19.2 \pm 2.15$ & $20.3 \pm 1.87$ & 0.41 \\
\hline Parabacteroides & $1.31 \pm 0.23$ & $0.99 \pm 0.20$ & 0.02 \\
\hline Prevotella $^{2}$ & $0.03 \pm 0.31$ & $0.03 \pm 0.30$ & 0.24 \\
\hline Actinobacteria & $5.45 \pm 1.05$ & $3.92 \pm 0.91$ & 0.03 \\
\hline Bifidobacterium & $3.68 \pm 0.85$ & $2.48 \pm 0.76$ & 0.03 \\
\hline Collinsella $^{2}$ & $0.14 \pm 0.24$ & $0.13 \pm 0.23$ & 0.87 \\
\hline Verrucomicrobia & $1.45 \pm 0.34$ & $1.10 \pm 0.29$ & 0.14 \\
\hline Akkermansia & $1.45 \pm 0.34$ & $1.10 \pm 0.29$ & 0.14 \\
\hline Proteobacteria & $\begin{array}{c}2.34 \pm 0.51 \\
n=18\end{array}$ & $\begin{array}{c}1.71 \pm 0.39 \\
n=68\end{array}$ & 0.15 \\
\hline
\end{tabular}

${ }^{1}$ Values are least-square means \pm pooled SEM; $n=15-18$ participants in a crossover design. ${ }^{2}$ Values are mean log-normalized sequence abundances \pm SE. Treatment effects of genera representing $\geq 0.5 \%$ of the total sequences were evaluated by using a mixed-model ANOVA (with fixed effects of period and treatment and a random effect of subject). 
Table 3. Bacterial phyla and genera of human participants at the end of the control diet period and each of the almond diet periods, each for three weeks ${ }^{1}$.

\begin{tabular}{|c|c|c|c|c|c|c|}
\hline \multicolumn{7}{|c|}{ Almond Treatments, $\%$ of Sequences ${ }^{1}$} \\
\hline & $\begin{array}{c}\text { Control } 0 \\
\text { g/Day }\end{array}$ & $\begin{array}{l}\text { Almond Butter } \\
42 \text { g/Day }\end{array}$ & $\begin{array}{l}\text { Chopped Almonds } \\
42 \text { g/Day }\end{array}$ & $\begin{array}{c}\text { Whole Roasted } \\
42 \text { g/Day }\end{array}$ & $\begin{array}{l}\text { Whole Raw } \\
42 \text { g/Day }\end{array}$ & $p$-Value \\
\hline \multicolumn{7}{|l|}{ PhylaandGenera } \\
\hline Firmicutes & $63.9 \pm 1.99$ & $64.2 \pm 1.99$ & $66.2 \pm 2.13$ & $66.2 \pm 1.99$ & $66.1 \pm 2.03$ & 0.68 \\
\hline Faecalibacterium & $4.39 \pm 0.68$ & $4.62 \pm 0.68$ & $4.48 \pm 0.70$ & $4.40 \pm 0.68$ & $4.94 \pm 0.68$ & 0.63 \\
\hline Coprococcus & $4.54 \pm 0.54$ & $4.60 \pm 0.54$ & $4.51 \pm 0.56$ & $5.06 \pm 0.54$ & $4.59 \pm 0.54$ & 0.73 \\
\hline Ruminococcus & $4.65 \pm 0.70$ & $4.73 \pm 0.69$ & $3.70 \pm 0.73$ & $4.22 \pm 0.69$ & $3.88 \pm 0.70$ & 0.39 \\
\hline Blautia & $2.09 \pm 0.33$ & $2.07 \pm 0.33$ & $2.36 \pm 0.34$ & $2.37 \pm 0.33$ & $2.24 \pm 0.33$ & 0.63 \\
\hline Dorea & $1.61 \pm 0.28$ & $1.71 \pm 0.28$ & $1.67 \pm 0.29$ & $1.77 \pm 0.28$ & $1.58 \pm 0.29$ & 0.87 \\
\hline Phascolarctobacterium $^{2}$ & $0.23 \pm 0.29$ & $0.24 \pm 0.29$ & $0.23 \pm 0.29$ & $0.20 \pm 0.29$ & $0.19 \pm 0.29$ & 0.70 \\
\hline Roseburia $^{2}$ & $0.47 \pm 0.14$ & $0.48 \pm 0.14$ & $0.83 \pm 0.14^{*}$ & $0.73 \pm 0.14$ & $0.73 \pm 0.14$ & $<0.01$ \\
\hline Lachnospira $^{2}$ & $0.49 \pm 0.15$ & $0.54 \pm 0.15$ & $0.80 \pm 0.15^{*}$ & $0.79 \pm 0.15$ * & $0.76 \pm 0.15^{\wedge}$ & 0.02 \\
\hline Dialister & $0.42 \pm 0.31$ & $0.44 \pm 0.31$ & $0.70 \pm 0.32$ & $0.74 \pm 0.31$ & $1.03 \pm 0.31 *$ & 0.01 \\
\hline Clostridium $^{2}$ & $0.42 \pm 0.08$ & $0.52 \pm 0.08$ & $0.54 \pm 0.09$ & $0.58 \pm 0.08$ & $0.48 \pm 0.08$ & 0.24 \\
\hline Streptococcus ${ }^{2}$ & $0.17 \pm 0.18$ & $0.23 \pm 0.18$ & $0.17 \pm 0.18$ & $0.18 \pm 0.18$ & $0.11 \pm 0.18$ & 0.09 \\
\hline Oscillospira & $0.54 \pm 0.07$ & $0.54 \pm 0.07$ & $0.75 \pm 0.07 *$ & $0.53 \pm 0.07$ & $0.51 \pm 0.07$ & 0.02 \\
\hline Bacteroidetes & $25.7 \pm 2.13$ & $27.1 \pm 2.14$ & $26.5 \pm 2.30$ & $25.7 \pm 2.14$ & $27.6 \pm 2.19$ & 0.90 \\
\hline Bacteroides & $19.2 \pm 2.15$ & $20.8 \pm 2.15$ & $20.4 \pm 2.26$ & $19.6 \pm 2.15$ & $20.6 \pm 2.18$ & 0.88 \\
\hline Parabacteroides & $1.31 \pm 0.23$ & $1.07 \pm 0.23$ & $0.89 \pm 0.23$ & $1.03 \pm 0.23$ & $0.93 \pm 0.23$ & 0.13 \\
\hline Prevotella ${ }^{2}$ & $0.03 \pm 0.31$ & $0.03 \pm 0.31$ & $0.04 \pm 0.31$ & $0.04 \pm 0.31$ & $0.03 \pm 0.31$ & 0.75 \\
\hline Actinobacteria & $5.45 \pm 1.05$ & $4.51 \pm 1.06$ & $3.77 \pm 1.11$ & $4.09 \pm 1.06$ & $3.20 \pm 1.07$ & 0.16 \\
\hline Bifidobacterium & $3.68 \pm 0.85$ & $2.68 \pm 0.85$ & $2.71 \pm 0.89$ & $2.53 \pm 0.85$ & $2.04 \pm 0.86$ & 0.19 \\
\hline Collinsella $^{2}$ & $0.14 \pm 0.24$ & $0.12 \pm 0.24$ & $0.12 \pm 0.25$ & $0.16 \pm 0.24$ & $0.13 \pm 0.24$ & 0.87 \\
\hline Verrucomicrobia & $1.45 \pm 0.34$ & $1.16 \pm 0.34$ & $1.10 \pm 0.36$ & $1.25 \pm 0.34$ & $0.87 \pm 0.35$ & 0.44 \\
\hline Akkermansia & $1.45 \pm 0.34$ & $1.16 \pm 0.34$ & $1.10 \pm 0.36$ & $1.25 \pm 0.34$ & $0.87 \pm 0.35$ & 0.44 \\
\hline Proteobacteria & $\begin{array}{c}2.34 \pm 0.51 \\
n=18\end{array}$ & $\begin{array}{c}1.93 \pm 0.51 \\
n=18\end{array}$ & $\begin{array}{c}1.88 \pm 0.55 \\
n=15\end{array}$ & $\begin{array}{c}1.75 \pm 0.51 \\
n=18\end{array}$ & $\begin{array}{c}1.29 \pm 0.52 \\
n=17\end{array}$ & 0.45 \\
\hline
\end{tabular}

${ }^{1}$ Values are least-square means \pm pooled SEM; $n=15-18$ participants in a crossover design. ${ }^{2}$ Values are mean log-normalized sequence abundances \pm SE. Treatment effects of genera representing $\geq 0.5 \%$ of the total sequences were evaluated by using a mixed-model ANOVA with post-hoc Dunnet's adjustments for multiple comparisons. Comparisons were made to the control condition. ${ }^{*} p \leq 0.05$ for comparison between the respective treatment condition and control condition; ${ }^{\wedge} p \leq 0.1$ for comparison between the respective treatment condition and control condition.

\section{Discussion}

Herein, we report that almond consumption induced changes in the relative abundance of microbes present within the human gastrointestinal tract and that the degree of almond processing differentially impacted the relative abundance of fecal bacterial genera. With regard to specific microbes, the results from this randomized controlled dietary intervention that provided $42 \mathrm{~g} / \mathrm{d}$ of almonds increased the relative abundance of Clostridium clusters IV and XIVa, including Roseburia, Clostridium, Lachnospira compared to the control diet period that was devoid of almonds. Comparisons between each of the four types of almonds (whole, whole roasted, roasted chopped, and butter) and control revealed that roasted chopped almonds increased the relative abundances of Roseburia, Lachnospira, and Oscillospira. Consumption of whole roasted almonds also increased the relative abundance of Lachnospira. There were no differences in the microbiota between the control group and the almond butter group.

We previously reported that almond processing affected metabolizable energy, with whole natural, whole roasted, and roasted chopped almonds providing up to $25 \%$ less metabolizable energy than predicted by calculated Atwater values [19]. Herein, the secondary analyses conducted on the same fecal samples from that previous study provide evidence that food form also impacts the composition of the human intestinal microbiota. Indeed, consumption of roasted, chopped almonds increased the relative abundances of Roseburia, Lachnospira, and Oscillospira compared to control. Whole roasted almonds also increased the relative abundance of Lachnospira, however, they only tended to increase Roseburia. Similarly, there was only a trend for increased relative abundances of Lachnospira and Roseburia with whole, natural almonds. However, whole, natural almonds increased the relative abundance of Dialister. As the whole natural almonds were the hardest and generated a lower 
number of particles than chopped roasted and roasted whole almonds, this may have not only reduced the metabolizable energy but also the bioaccessibility of nutrients for microbial metabolism. Additional evidence for the relationship between metabolizable energy and the microbiota is provided through the comparisons between almond butter and control. Indeed, disruption of the plant cell wall by roasting and grinding the almonds into almond butter resulted in similar microbial profiles to that of the control period, which is consistent with our previously reported finding that the measured metabolizable energy of almond butter was not different from the calculated value [19]. Overall, these results indicate that roasting, which reduces the fracture force, hardness and subsequently particle size of almonds following mastication [29], as well as the metabolizable energy [19], are also relevant factors that affect the human gastrointestinal microbiota.

Our findings are supported by previous clinical research that reported that up to $82 \mathrm{~g} / \mathrm{day}$ of almonds did not affect alpha-diversity but did increased the abundance of several Clostridium spp. [30]. Similarly, a clinical trial assessing walnut consumption revealed that $42 \mathrm{~g} /$ day of walnuts increased Roseburia, Clostridum and Dialister, and reduced the relative abundances of Bifidobacterium [31]. Although there are not preclinical studies investigating the impact of almond consumption on gastrointestinal microbiota, our results are supported by a rodent study demonstrating that walnuts increased the relative abundances of Firmicutes, including Clostridium [32], Roseburia, and Oscillospira [33]. In vitro work has revealed that finely ground almonds increase butyrate concentrations [20]. Roseburia spp. produce high levels of butyrate in vitro, possess the butyryl coenzyme A (CoA): acetate CoA transferase, and may account for a significant proportion of butyrate-producing bacteria in the human colon [34-36]. Thus, the increase in the relative abundance of Roseburia following almond consumption may be important because reduced butyrate-producing bacteria has been linked to metabolic diseases including obesity [37], type 2 diabetes [2], and cardiovascular disease [38]. In addition, as our results revealed an increase in the relative abundance of Roseburia spp., we can hypothesize that these changes in the microbiota may have increased colonic butyrate concentrations in the study participants. However, additional human studies on almond consumption that measure fecal butyrate concentrations are needed to test this hypothesis as well as determine if changes in the gastrointestinal microbiota also contribute to metabolic health outcomes including adiposity, glycemia, and blood cholesterol concentrations.

In addition to providing a good source of dietary fiber, almonds are also rich in unsaturated fatty acids. Unsaturated fatty acids, as opposed to saturated fatty acids, have been shown to have antimicrobial properties through the inhibition of bacterial fatty acid synthesis and growth [39], and also reduce microbial adhesion to mucus [40]. Thus, the increase in the relative abundance of Roseburia spp. following almond consumption in the present study may be related to their ability to metabolize fatty acids. Consumption of polyunsaturated fatty acids may modulate the composition of the gastrointestinal microbiome due to the differing abilities of bacteria to metabolize long-chain fatty acids. For example, in vitro studies have reported that Roseburia spp. are among the most active linoleic acid metabolizing bacteria in the human intestine [12-14].

Although the study participants' age range was fairly broad, ranging from 32-78 years of age, 15 of the 18 study participates were 50 years of age or older. Therefore, the gastrointestinal microbiota characteristics of the participants in the current study would generally be reflective of a slightly older population. As the relative abundance of Roseburia spp. has been reported to be negatively associated with age [41,42], almond consumption may help delay age-related microbiota changes. However, as this study was fairly short-term (three weeks per diet period, 20 weeks total), additional longitudinal research on almond consumption and the microbiota in the context of aging is necessary.

The strength of this study is the use of a complete feeding, randomized controlled, cross-over trial with washout periods between each treatment to assess the impact of almond processing on the human gastrointestinal microbiota. Study limitations include lack of bacterial fermentative end-products such as the short-chain fatty acids acetate, propionate, and butyrate. In summary, almond consumption and the form of the almonds differentially impacted the human gastrointestinal microbiota. Nutrients that 
might not be available to the body through digestion in the upper intestine due to the food matrix can become substrates for microbiota metabolism in the large intestine. In this study of different forms of almonds, when these nutrients enter the large intestine, these substrates alter the composition of the microbiota. These results suggest the gastrointestinal microbiota may contribute to the underlying mechanisms of the beneficial health effects of almond consumption.

Supplementary Materials: The following are available online at http:/ /www.mdpi.com/2072-6643/10/2/126/s1, Supplemental Figure S1: Phylogenetic Diversity, Supplemental Figure S2: Observed OTUs, Supplemental Figure S3: Unweighted Unifrac PCoA, Supplemental Figure S4: Weighted Unifrac PCoA.

Acknowledgments: The authors thank Heather Guetterman for her technical assistance.

Author Contributions: D.J.B. and J.A.N. designed and conducted the original research trial; A.M.T., K.S.S. and H.D.H. conducted the microbiota analyses; A.M.T. and H.D.H. analyzed the data; A.M.T., D.J.B. and H.D.H. wrote the manuscript; and H.D.H. has primary responsibility for the final content. All authors read and approved the final manuscript.

Conflicts of Interest: Partial support for this project was provided by the Almond Board of California and the USDA ARS. Baer and Novotny are employed by the USDA ARS and have received funding from the Almond Board of California. Holscher and Swanson have received funding from the USDA ARS. Taylor was funded by a Department of Food Science and Human Nutrition Graduate Fellowship and a College of Agricultural, Consumer, and Environmental Sciences Undergraduate Research Scholarship.

\section{Abbreviations}

Beltsville Human Nutrition Research Center (BHNRC), Body mass index (BMI), Principal coordinates analysis (PCoA), operational taxonomic unit (OTU), USDA (United States Department of Agriculture).

\section{References}

1. Sonnenburg, J.L.; Bäckhed, F. Diet-microbiota interactions as moderators of human metabolism. Nature 2016, 535, 56-64. [CrossRef] [PubMed]

2. Qin, J.; Li, Y.; Cai, Z.; Li, S.; Zhu, J.; Zhang, F.; Liang, S.; Zhang, W.; Guan, Y.; Shen, D. A metagenome-wide association study of gut microbiota in type 2 diabetes. Nature 2012, 490, 55-60. [CrossRef] [PubMed]

3. Wu, G.D.; Chen, J.; Hoffmann, C.; Bittinger, K.; Chen, Y.-Y.; Keilbaugh, S.A.; Bewtra, M.; Knights, D.; Walters, W.A.; Knight, R.; et al. Linking Long-Term Dietary Patterns with Gut Microbial Enterotypes. Science 2011, 334, 105-109. [CrossRef] [PubMed]

4. David, L.A.; Maurice, C.F.; Carmody, R.N.; Gootenberg, D.B.; Button, J.E.; Wolfe, B.E.; Ling, A.V.; Devlin, A.S.; Varma, Y.; Fischbach, M.A.; et al. Diet rapidly and reproducibly alters the human gut microbiome. Nature 2013, 505, 559-563. [CrossRef] [PubMed]

5. Kaczmarek, J.L.; Musaad, S.M.; Holscher, H.D. Time of day and eating behaviors are associated with the composition and function of the human gastrointestinal microbiota. Am. J. Clin. Nutr. 2017, 106, 1220-1231. [CrossRef] [PubMed]

6. Martínez, I.; Lattimer, J.M.; Hubach, K.L.; Case, J.A.; Yang, J.; Weber, C.G.; Louk, J.A.; Rose, D.J.; Kyureghian, G.; Peterson, D.A.; et al. Gut microbiome composition is linked to whole grain-induced immunological improvements. ISME J. 2013, 7, 269-280. [CrossRef] [PubMed]

7. Holscher, H.D.; Caporaso, J.G.; Hooda, S.; Brulc, J.M.; Fahey, G.C.J.; Swanson, K.S.; Fahey, G.C., Jr.; Swanson, K.S. Fiber supplementation influences phylogenetic structure and functional capacity of the human intestinal microbiome: Follow-up of a randomized controlled trial. Am. J. Clin. Nutr. 2015, 101, 55-64. [CrossRef] [PubMed]

8. Holscher, H.D.; Bauer, L.L.; Vishnupriya, G.; Pelkman, C.L.; Fahey, G.C.; Swanson, K.S.; Gourineni, V.; Pelkman, C.L.; Fahey, G.C., Jr.; Swanson, K.S. Agave inulin supplementation affects the fecal microbiota of healthy adults participating in a randomized, double-blind, placebo-controlled, crossover trial. J. Nutr. 2015, 145, 2025-2032. [CrossRef] [PubMed]

9. Davis, L.M.G.; Martínez, I.; Walter, J.; Goin, C.; Hutkins, R.W. Barcoded pyrosequencing reveals that consumption of galactooligosaccharides results in a highly specific bifidogenic response in humans. PLoS ONE 2011, 6, e25200. [CrossRef] [PubMed] 
10. Martínez, I.; Kim, J.; Duffy, P.R.; Schlegel, V.L.; Walter, J. Resistant starches types 2 and 4 have differential effects on the composition of the fecal microbiota in human subjects. PLoS ONE 2010, 5, e15046. [CrossRef] [PubMed]

11. Holscher, H.D. Dietary Fiber and Prebiotics and the Gastrointestinal Microbiota. Gut Microbes 2017, 8, 172-184. [CrossRef] [PubMed]

12. Devillard, E.; McIntosh, F.M.; Paillard, D.; Thomas, N.A.; Shingfield, K.J.; Wallace, R.J. Differences between human subjects in the composition of the faecal bacterial community and faecal metabolism of linoleic acid. Microbiology 2009, 155, 513-520. [CrossRef] [PubMed]

13. Gorissen, L.; Raes, K.; Weckx, S.; Dannenberger, D.; Leroy, F.; De Vuyst, L.; De Smet, S. Production of conjugated linoleic acid and conjugated linolenic acid isomers by Bifidobacterium species. Appl. Microbiol. Biotechnol. 2010, 87, 2257-2266. [CrossRef] [PubMed]

14. Devillard, E.; McIntosh, F.M.; Duncan, S.H.; Wallace, R.J. Metabolism of linoleic acid by human gut bacteria: Different routes for biosynthesis of conjugated linoleic acid. J. Bacteriol. 2007, 189, 2566-2570. [CrossRef] [PubMed]

15. Devkota, S.; Wang, Y.; Musch, M.W.; Leone, V.; Fehlner-Peach, H.; Nadimpalli, A.; Antonopoulos, D.A.; Jabri, B.; Chang, E.B. Dietary-fat-induced taurocholic acid promotes pathobiont expansion and colitis in Il10-/- mice. Nature 2012, 487, 104-108. [CrossRef] [PubMed]

16. Kris-Etherton, P.M.; Hu, F.B.; Ros, E.; Sabaté, J. The role of tree nuts and peanuts in the prevention of coronary heart disease: Multiple potential mechanisms. J. Nutr. 2008, 138, 1746S-1751S. [CrossRef] [PubMed]

17. Bao, Y.; Han, J.; Hu, F.B.; Giovannucci, E.L.; Stampfer, M.J.; Willett, W.C.; Fuchs, C.S. Association of nut consumption with total and cause-specific mortality. N. Engl. J. Med. 2013, 369, 2001-2011. [CrossRef] [PubMed]

18. Rajaram, S.; Sabaté, J. Nuts, body weight and insulin resistance. Br. J. Nutr. 2006, 96 (Suppl. S2), S79-S86. [CrossRef] [PubMed]

19. Gebauer, S.K.; Novotny, J.A.; Bornhorst, G.M.; Baer, D.J. Food processing and structure impact the metabolizable energy of almonds. Food Funct. 2016, 7, 4231-4238. [CrossRef] [PubMed]

20. Mandalari, G.; Nueno-Palop, C.; Bisignano, G.; Wickham, M.S.J.; Narbad, A. Potential prebiotic properties of almond (Amygdalus communis L.) seeds. Appl. Environ. Microbiol. 2008, 74, 4264-4270. [CrossRef] [PubMed]

21. Sokol, H.; Pigneur, B.; Watterlot, L.; Lakhdari, O.; Bermudez-Humaran, L.G.; Gratadoux, J.J.; Blugeon, S.; Bridonneau, C.; Furet, J.P.; Corthier, G.; et al. Faecalibacterium prausnitzii is an anti-inflammatory commensal bacterium identified by gut microbiota analysis of Crohn disease patients. Proc. Natl. Acad. Sci. USA 2008, 105, 16731-16736. [CrossRef] [PubMed]

22. Liu, T.-W.; Cephas, K.D.; Holscher, H.D.; Kerr, K.R.; Mangian, H.F.; Tappenden, K.A.; Swanson, K.S. Nondigestible Fructans Alter Gastrointestinal Barrier Function, Gene Expression, Histomorphology, and the Microbiota Profiles of Diet-Induced Obese C57BL/6J Mice 1-3. J. Nutr. 2016, 146, 1-8. [CrossRef] [PubMed]

23. Zhang, X.; Shen, D.; Fang, Z.; Jie, Z.; Qiu, X.; Zhang, C.; Chen, Y.; Ji, L. Human Gut Microbiota Changes Reveal the Progression of Glucose Intolerance. PLoS ONE 2013, 8. [CrossRef] [PubMed]

24. Venable, E.B.; Fenton, K.A.; Braner, V.M.; Reddington, C.E.; Halpin, M.J.; Heitz, S.A.; Francis, J.M.; Gulson, N.A.; Goyer, C.L.; Bland, S.D.; et al. Effects of Feeding Management on the Equine Cecal Microbiota. J. Equine Vet. Sci. 2017, 49, 113-121. [CrossRef]

25. Caporaso, J.G.; Kuczynski, J.; Stombaugh, J.; Bittinger, K.; Bushman, F.D.; Costello, E.K.; Fierer, N.; Peña, A.G.; Goodrich, J.K.; Gordon, J.I.; et al. QIIME allows analysis of high-throughput community sequencing data. Nature 2010, 7, 335-336. [CrossRef] [PubMed]

26. Caporaso, J.G.; Lauber, C.L.; Walters, W.A.; Berg-Lyons, D.; Huntley, J.; Fierer, N.; Owens, S.M.; Betley, J.; Fraser, L.; Bauer, M.; et al. Ultra-high-throughput microbial community analysis on the Illumina HiSeq and MiSeq platforms. ISME J. 2012, 6, 1621-1624. [CrossRef] [PubMed]

27. Schoch, C.L.; Seifert, K.A.; Huhndorf, S.; Robert, V.; Spouge, J.L.; Levesque, C.A.; Chen, W.; Consortium, F.B. Nuclear ribosomal internal transcribed spacer (ITS) region as a universal DNA barcode marker for Fungi. Proc. Natl. Acad. Sci. USA 2012, 109, 6241-6246. [CrossRef] [PubMed]

28. Bokulich, N.A.; Subramanian, S.; Faith, J.J.; Gevers, D.; Gordon, J.I.; Knight, R.; Mills, D.A.; Caporaso, J.G. Quality-filtering vastly improves diversity estimates from Illumina amplicon sequencing. Nat. Methods 2013, 10, 57-59. [CrossRef] [PubMed] 
29. Grundy, M.M.L.; Grassby, T.; Mandalari, G.; Waldron, K.W.; Butterworth, P.J.; Berry, S.E.E.; Ellis, P.R. Effect of mastication on lipid bioaccessibility of almonds in a randomized human study and its implications for digestion kinetics, metabolizable energy, and postprandial lipemia. Am. J. Clin. Nutr. 2015, 101, 25-33. [CrossRef] [PubMed]

30. Ukhanova, M.; Wang, X.; Baer, D.J.; Novotny, J.A.; Fredborg, M.; Mai, V. Effects of almond and pistachio consumption on gut microbiota composition in a randomised cross-over human feeding study. Br. J. Nutr. 2014, 111, 2146-2152. [CrossRef] [PubMed]

31. Holscher, H.D.; Guetterman, H.M.; Swanson, K.S.; An, R.; Matthan, N.R.; Lichtenstein, A.H.; Novotny, J.A.; Baer, D.J. Walnut consumption alters the gastrointestinal microbiota, microbial-derived secondary bile acids, and health markers in healthy adults: A randomized controlled trial. J. Nutr. 2018. [CrossRef]

32. Nakanishi, M.; Chen, Y.; Qendro, V.; Miyamoto, S.; Weinstock, E.; Weinstock, G.M.; Rosenberg, D.W. Effects of walnut consumption on colon carcinogenesis and microbial community structure. Cancer Prev. Res. 2016, 9, 692-703. [CrossRef] [PubMed]

33. Byerley, L.O.; Samuelson, D.; Blanchard, E.; Luo, M.; Lorenzen, B.N.; Banks, S.; Ponder, M.A.; Welsh, D.A.; Taylor, C.M. Changes in the Gut Microbial Communities Following Addition of Walnuts to the Diet. J. Nutr. Biochem. 2017, 48, 94-102. [CrossRef] [PubMed]

34. Pryde, S.E.; Duncan, S.H.; Hold, G.L.; Stewart, C.S.; Flint, H.J. The microbiology of butyrate formation in the human colon. FEMS Microbiol. Lett. 2002, 217, 133-139. [CrossRef] [PubMed]

35. Duncan, S.H.; Hold, G.L.; Barcenilla, A.; Stewart, C.S.; Flint, H.J. Roseburia intestinalis sp. nov., a novel saccharolytic, butyrate-producing bacterium from human faeces. Int. J. Syst. Evol. Microbiol. 2002, 52, 1615-1620. [CrossRef] [PubMed]

36. Duncan, S.H.; Hold, G.L.; Harmsen, H.J.; Stewart, C.S.; Flint, H.J. Growth requirements and fermentation products of Fusobacterium prausnitzii, and a proposal to reclassify it as Faecalibacterium prausnitzii gen. nov., comb. nov. Int. J. Syst. Evol. Microbiol. 2002, 52, 2141-2146. [PubMed]

37. Le Chatelier, E.; Nielsen, T.; Qin, J.; Prifti, E.; Hildebrand, F.; Falony, G.; Almeida, M.; Arumugam, M.; Batto, J.-M.; Kennedy, S.; et al. Richness of human gut microbiome correlates with metabolic markers. Nature 2013, 500, 541-546. [CrossRef] [PubMed]

38. Karlsson, F.H.; Fåk, F.; Nookaew, I.; Tremaroli, V.; Fagerberg, B.; Petranovic, D.; Bäckhed, F.; Nielsen, J. Symptomatic atherosclerosis is associated with an altered gut metagenome. Nat. Commun. 2012, 3, 1245. [CrossRef] [PubMed]

39. Zheng, C.J.; Yoo, J.-S.; Lee, T.-G.; Cho, H.-Y.; Kim, Y.-H.; Kim, W.-G. Fatty acid synthesis is a target for antibacterial activity of unsaturated fatty acids. FEBS Lett. 2005, 579, 5157-5162. [CrossRef] [PubMed]

40. Kankaanpää, P.E.; Salminen, S.J.; Isolauri, E.; Lee, Y.K. The influence of polyunsaturated fatty acids on probiotic growth and adhesion. FEMS Microbiol. Lett. 2001, 194, 149-153. [CrossRef] [PubMed]

41. Biagi, E.; Franceschi, C.; Rampelli, S.; Severgnini, M.; Ostan, R.; Turroni, S.; Consolandi, C.; Quercia, S.; Scurti, M.; Monti, D.; et al. Gut Microbiota and Extreme Longevity. Curr. Biol. 2016, 26, 1480-1485. [CrossRef] [PubMed]

42. Wang, F.; Yu, T.; Huang, G.; Cai, D.; Liang, X.; Su, H.; Zhu, Z.; Li, D.; Yang, Y.; Shen, P.; et al. Gut Microbiota community and its assembly associated with age and diet in Chinese centenarians. J. Microbiol. Biotechnol. 2015, 25, 1195-1204. [CrossRef] [PubMed]

(C) 2018 by the authors. Licensee MDPI, Basel, Switzerland. This article is an open access article distributed under the terms and conditions of the Creative Commons Attribution (CC BY) license (http:// creativecommons.org/licenses/by/4.0/). 